\title{
Discussion Paper: \\ Children in out-of-home care: What do medical students learn about them?
}

\author{
K. Thornton
}

\begin{abstract}
Out-of-home care (OOHC) refers to alternative care, such as foster care, kinship care or residential care, for children and young people up to 18 years old who are unable to safely live with their families. Child maltreatment is common, and 1 in 35 children in Australia received child protection services in 2014-2015. Placement in OOHC is considered an intervention of last resort, meaning that those in care are the highest risk cohort receiving protective services.

I conducted a small pilot study to explore what is currently taught to future doctors about children in $\mathrm{OOHC}$ and found that there is no formal teaching about these children in the University of Melbourne Doctor of Medicine course. Child abuse and neglect is covered in the paediatric curriculum, and mandatory reporting appears to be well covered. After reflecting on the implications of this omission, I considered a number of ways material about this topic could be implemented into medical school curricula.
\end{abstract}

Keywords: medical education; child; child abuse; education, professional.

\section{Correspondence}

Katherine Thornton, GP and academic registrar (at the time of the pilot study)

Department of General Practice

200 Berkeley Street

University of Melbourne

Carlton 3053

Australia

Tel: +61 383447276

Email: katherine.thornton@unimelb.edu.au 


\section{Introduction}

I first met Jake on a busy afternoon in a clinic where I was working as a GP registrar. He was a shy 3-year-old boy brought in by Sarah, his mother's cousin and his current carer. Sarah wanted to discuss his poor sleep. After a few minutes, I realised that there were many other issues that needed addressing. Jake had been neglected by his parents when he was younger, and Sarah was concerned about his speech. She didn't know much about his past medical history or his immunisation status. She commented that Jake was clingy and anxious—was this normal for a 3-year-old? By the end of the consultation, I really wanted to help improve Jake's health but was uncertain about the best way to approach it.

Most children who enter out-of-home care have experienced early life trauma and adversity, like Jake. Out-of-home care (OOHC) refers to alternative care, such as foster care, kinship care or residential care, for children and young people up to 18 years old who are unable to safely live with their families. General practitioners (GPs), in conjunction with many other healthcare professionals, provide care to these children, who often have complex needs. Children in OOHC are known to be at heightened risk of missing preventive healthcare, such as immunisation and dental checks, experiencing chronic and complex health conditions and having poorer short- and long-term health outcomes compared with other children (Webster, 2012). They are at increased risk of cumulative harm caused by under-investigation of apparently minor ailments that have a cumulative effect on emotional, developmental and physical health (Szilagyi, 2012).

\section{Method}

Despite the known health issues for children in OOHC, I cannot recall any formal teaching about children in OOHC when I was a medical student. As a GP registrar, I conducted a preliminary review to explore what is currently taught to future doctors about children in OOHC. In the UK, there has been an increased focus on the needs of these children. In 2015, competencies required for healthcare staff (including GPs) who work with children in care were updated (Intercollegiate, 2015). However, I was unable to find any research demonstrating what Australian medical students are taught about children in OOHC. I investigated the curricula of three university medical courses in Victoria and was unable to find any evidence of formal teaching about children in OOHC. My approach was flexible, given the different structures of each of the medical schools. I contacted the relevant year-level coordinators or subject coordinators at each university via email or phone. One limitation was that it was challenging to make contact with some relevant people, requiring multiple attempts. Another limitation was that I only approached the three Victorian medical schools due to time restraints, therefore meaning that I cannot comment on the curriculum of other Australian medical schools.

In particular, I explored the curriculum of one Australian university in detail. I found that while this course had no formal teaching about children in OOHC, child abuse and neglect were covered in the paediatric curriculum, and mandatory reporting appeared to be well covered. In addition, there was some education about vulnerable families and family violence in the women's health placement. 


\section{Discussion}

Child neglect and abuse and child protection may be complex topics to teach, and they cross many different domains and disciplines. Medical school curricula are already crowded, leaving minimal space for additional material. It may also be challenging to recruit appropriately-skilled staff to teach in this multidisciplinary field. Teaching medical students about trauma (including child abuse) is a topical issue. A recent article published in the MJA by Matta, Woodward-Kron, Petty and Salzberg (2016) argued the importance of trauma-informed medical education. The authors recommended that trauma-informed education should be incorporated into undergraduate, prevocational and specialist training programs. They include child abuse and family violence as forms of traumatic experience.

\section{Conclusion}

I believe material could be incorporated into medical school courses relatively easily, either using a 30-minute asynchronous webinar that students could watch in their own time or a tutorial delivered by university staff. Information could be presented about how common child abuse issues are in Australia, as well as the ways in which child maltreatment can impact on short- and long-term health outcomes. Additionally, students could undertake a placement within a child protection agency, where they could learn firsthand about children in $\mathrm{OOHC}$ from the multidisciplinary teams working in such organisations.

A national clinical assessment framework exists in Australia, which provides some practical guidance to healthcare professionals regarding children in OOHC (Australian Government, 2011). This includes information about a comprehensive health assessment that should be done within 3 months of children entering care and information about Medicare item numbers to use. This framework was designed to aid health professionals in improving the health outcomes for children in OOHC. However, this document does not address the competencies required by health practitioners to care for children in $\mathrm{OOHC}$ in the way that UK guidelines do.

Increasing awareness of this national clinical assessment framework may be helpful in improving the health of children in care. One way to do this may be to encourage medical students to be familiar with the framework before undertaking GP placements. They could then refer to it if they see a child in OOHC during their placement. If their supervisor is unaware of the framework, they may also be able to introduce their supervisor to it.

\section{Summary}

Child maltreatment is common, and 1 in 35 children in Australia received child protection services in 2014-2015 (AIHW, 2016). Placement in OOHC is considered an intervention of last resort, meaning those in care are the highest risk cohort receiving protective services. On 30 June 2016, approximately 46,500 children were living in OOHC (AIHW, 2017). This number has steadily increased in the last 5 years. Indeed, the rate of children in $\mathrm{OOHC}$ in Australia is higher than the rate of children with cystic 
fibrosis or type 1 diabetes mellitus (Carbone, Sawyer, Searle, \& Robinson, 2007). To minimise the impact of child trauma on future development, educating future doctors about this group is critical.

\section{Acknowledgements}

Thanks to my supervisors Professor Meredith Temple-Smith and Dr Susan Webster for their assistance with this research project.

\section{Funding and conflicts of interest}

Kate Thornton received funding from the Australian Department of Health as an academic registrar.

Ethics approval was not required for this project.

\section{References}

Australian Government, Department of Health. (2011). National clinical assessment framework for children and young people in out-of-home care (OOHC). Retrieved from http://health.gov.au/internet/publications/publishing.nsf/Content/ncaf-cypoohc-toc

Australian Institute of Health and Welfare (AIHW). (2016). Child protection Australia 2014-2015. Retrieved from http://www.aihw.gov.au/WorkArea/DownloadAsset. aspx?id=60129554973

Australian Institute of Health and Welfare (AIHW). (2017). Child protection Australia 2015-2016. Retrieved from https://www.aihw.gov.au/getmedia/bce377ec-1b764cc5-87d9-d0541fca586c/20479.pdf.aspx?inline=true

Carbone, J., Sawyer, M. G., Searle, A. K., \& Robinson, P. J. (2007). The healthrelated quality of life of children and adolescents in home-based foster care. Quality of Life Research, 16(7), 1157-1166.

Royal College of Nursing and the Royal College of Paediatrics and Child Health (RCPCH). (2015). Looked after children: Knowledge, skills and competences of healthcare staff —Intercollegiate role framework. Retrieved from https://www. rcpch.ac.uk/sites/default/files/Looked_after_children_Knowledge_skills_and_ competence_of_healthcare_staff.pdf

Matta, G., Woodward-Kron, R. E., Petty, S., \& Salzberg, M. R. (2016). Eliciting and responding to patient histories of abuse and trauma: Challenges for medical education. Medical Journal of Australia, 205(6), 248-249. doi:10.5694/ mja16.00216

Szilagyi, M. (2012). The pediatric role in the care of children in foster and kinship care. Pediatrics in Review, 33(11), 496-507. doi:10.1542/pir.33-496

Webster, S., Temple-Smith, M., \& Smith, A. (2012). Children and young people in out-of-home care: Improving access to primary care. Australian Family Physician, 41(10), 819-822. 